\title{
LEGISLADOR E TIRANO: COMO DISTINGUI-LOS? UMA REFLEXÃO SOB A PERSPECTIVA DE JEAN-JACQUES ROUSSEAU
}

\section{LEGISLATOR AND TYRANT: HOW TO DISTINGUISH THEM? A REFLECTION FROM THE PERSPECTIVE OF JEAN-JACQUES ROUSSEAU}

Adriano Eurípedes Medeiros Martins*

\begin{abstract}
RESUMO
Jean-Jacques Rousseau qualifica o Legislador como um agente excepcional no processo de contenção da corrupção e de promoção dos valores republicanos. No desenvolvimento de sua atividade competirá ao Legislador conhecer o povo para o qual será instituído um sistema de leis, e que estas leis se harmonizem com o interesse geral e a soberania desse mesmo povo. Para tal tarefa, os poderes do Legislador são muito acentuados. Muito poder sob o controle de um indivíduo leva-nos, necessariamente à seguinte questão: e se ocorrer o abuso? Resposta: o Legislador tornar-se-á um tirano. Mas, dado certo concerto da sociedade civil, a tirania poderá ser evitada.
\end{abstract}

PALAVRAS-CHAVE: Jean-Jacques Rousseau. Legislador. Tirano.

\begin{abstract}
Jean -Jacques Rousseau describes the Lawmaker as an outstanding agent in the process of curbing corruption and promoting republican values. In developing its activity will compete to the Lawmaker know the people for whom a system of laws will be introduced, and that these laws be harmonized with the general interest and the sovereignty of the same people. For this task, the Lawmaker's powers are very pronounced. Much power under the control of an individual leads us necessarily to the next question: what if there is abuse? Answer: Lawmaker will become a tyrant. But given certain covenant of civil society, the tyranny can be avoided.

KEYWORDS: Jean -Jacques Rousseau. Lawmaker. Tyrant.
\end{abstract}

\footnotetext{
* Graduado em Filosofia pela Universidade Federal de Uberlândia (UFU). Mestre e Doutor em Filosofia pela Universidade Federal de Minas Gerais (UFMG). Pós-doutorando em Filosofia pela UFU.
} 
Jean-Jacques Rousseau, cidadão de Genebra, qualifica o Legislador como um agente excepcional no processo de contenção da corrupção e de promoção dos valores autenticamente republicanos. No desenvolvimento de sua efetiva atividade competirá ao Legislador conhecer o povo para o qual será instituído um sistema de leis, e que estas leis se harmonizem com o interesse geral e a soberania desse mesmo povo. Para tal tarefa, os poderes do Legislador são muito acentuados. Muito poder sob o controle de um indivíduo leva-nos, necessariamente à seguinte questão: e se ocorrer o abuso? Resposta: o Legislador tornar-se-á um tirano. É esta a proposta analítica para o presente texto.

Comecemos pela abordagem da escolha do momento propício em que um povo receberá um conjunto de leis, pois isso terá reflexo direto no ato de fundação do Estado republicano. É justamente nesse instante que a distinção entre o Legislador e o tirano começa a se delinear mais nitidamente. Nas próprias palavras de Rousseau, temos que considerar " $a$ escolha do momento de instituição representa um dos caracteres mais seguros pelos quais se pode distinguir a obra do Legislador da de um tirano"1. Nesse caso, Rousseau aponta que o Legislador deverá instituir tais leis num momento, no mínimo, de relativa ordem e paz no interior do corpo político. Já se esse corpo político estiver passando por um período conturbado por convulsões sociais, aí teremos um terreno fértil para a ação do tirano ${ }^{2}$. Logo, se não houver ordem ou paz teremos um momento de perturbação ou social ou política ou econômica; talvez até mesmo uma amálgama de todas. Será deste cenário que regularmente emerge a figura, também uma personagem de exceção, do tirano ${ }^{3}$.

Podemos apontar outra distinção significativa entre essas duas personagens: o Legislador guia e esclarece; o tirano coage e usurpa. É nesse aspecto que Cassirer, ao tratar desse aspecto da tirania, chama-nos a atenção para a seguinte situação: “A coação pior e mais implacável da sociedade reside nesse poder que ela exerce não somente sobre nossas ações exteriores, mas também sobre todos os nossos estímulos interiores, sobre nossos pensamentos

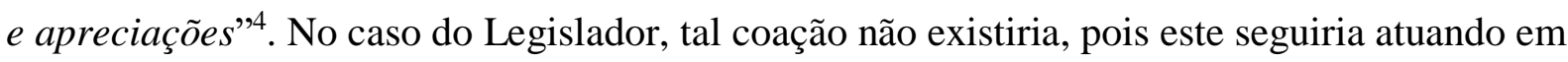
favor do interesse geral. Aqui, portanto, a soberania seguiria nas mãos do povo, a liberdade e a igualdade não seriam usurpadas. $\mathrm{O}$ sistema de leis da sociedade continuaria sendo o grande guia dos cidadãos livres e soberanos. Por outro lado, como nos aponta Cassirer, com a tirania

\footnotetext{
${ }^{1}$ ROUSSEAU. Du Contrat Social. In: Oeuvres Complètes-Gallimard, vol. 3, p. 390.

2 "A instituição [em] tempos convulsos é sempre tirânica". MACHADO apud ROUSSEAU. Textos Escolhidos/Rousseau. vol. I, p. 125.

${ }^{3}$ Cf. Burgelin. La philosophie de l'existence de J.-J. Rousseau, p. 560.

${ }^{4}$ CASSIRER. A questão Jean-Jacques Rousseau, p. 46.
} 
ou um modelo político com tal aptidão, teremos outro cenário. Nesse último, “não somos nós

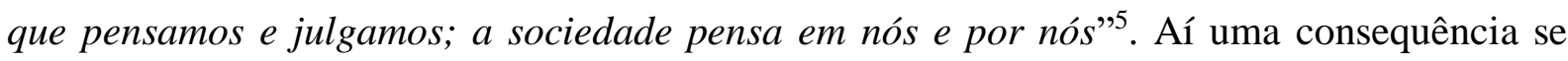
torna patente: a soberania deslocou-se das mãos dos cidadãos para as do governo. Sabemos que, tal situação atenta flagrantemente contra a soberania do povo, pois aqui ela estaria nas mãos do governo e em contradição com a vontade geral; o que evidenciaria o abuso da mesma. Assim, o tirano agirá como se fosse um ator exógeno à sociedade. O corpo político passa, então, a ter um governante que se põe acima ou a margem do sistema de leis. Enfim, o poder executivo passa a usurpar o poder legislativo e a soberania popular. E tal usurpação redundará em formas políticas ou institucionais de coação aos membros da referida sociedade ${ }^{6}$.

Mas, e se o povo aceitar passivamente esse ambiente de coação e usurpação? Essa questão nos remete à temática de qual é o povo ideal à legislação. Nesse caso, não podemos deixar de lado os limites que a corrupção impõe a toda ação levada a cabo nos domínios públicos ${ }^{7}$. Nesse prisma, podemos abordar a questão pela ótica do tirano, ou seja, nos perguntamos sobre qual seria o povo apto à tirania ${ }^{8}$ - um guia que seja usurpador do Estado -? Desde já, Rousseau defenderá que há povos aptos à legislação e outros à usurpação da sua vontade, liberdade e soberania. Conforme o Genebrino, poderemos estar diante do seguinte cenário:

Qual o povo, pois, que está apto à legislação? Aquele que encontrando-se já ligado por qualquer laço de origem, interesse ou convenção, ainda não sofreu o verdadeiro jugo das leis; que não tem nem costumes nem superstições muito arraigadas; que não teme ser arrasado por uma invasão súbita; que, sem imiscuir-se nas brigas entre seus vizinhos, pode resistir sozinho a cada um deles, ou ligar-se a um para expulsar o outro; aquele de que cada membro pode ser conhecido por todos e no qual não se está de modo algum forçado a sobrecarregar um homem com um fardo mais pesado do que possa suportar; o que pode viver sem os outros povos e que qualquer outro povo pode dispensar; o que não é nem rico nem pobre e pode bastar-

\footnotetext{
5 Ibid., p. 46.

${ }^{6}$ Esclarecemos que Rousseau defende a democracia direta, isto é, todo poder - o tempo todo - pertence ao povo. Os outros poderes são delegações deste poder originário e inigualável. O poder do cidadão não pode ser alienado e deve ser exercido, obrigatoriamente, por cada indivíduo pertencente ao corpo político.

7 O Genebrino defende que temos uma natureza humana naturalmente boa e que foi o desenvolvimento de formas de vida coletivas e sócias que degeneraram esta mesma natureza humana. $\mathrm{O}$ que pode ser expresso sinteticamente da seguinte maneiro: o homem nasce bom, mas a sociedade o corrompe.

${ }^{8}$ Ressaltamos que, aqui há uma característica comum entre o Legislador e o tirano, a saber, ambos só podem ter existência no interior de uma sociedade civil. Nenhum deles teria existido no estado de natureza ou nos estados de transição.
} 
se a si mesmo; enfim, aquele que une, à consistência de um povo antigo, a docilidade de um povo novo. ${ }^{9}$

Entretanto, se invertermos as premissas acima, teremos o cenário apto à ação do tirano. Acreditamos que um povo apto à legislação não tenha que ter, naturalmente, o somatório de todos esses condicionantes. Contudo, devemos atentar para o contrário desses elementos como sendo capaz de inviabilizar o estabelecimento de um sistema de leis adequado ao interesse geral. Assim, bastaria o desvirtuamento de um desses fatores para que a figura do tirano pudesse emergir no seio da sociedade.

Dada a afirmação acima podemos deduzir que o povo poderá ser convencido a agir contra si mesmo. A própria existência do tirano confirmaria isso. Por isso, o ato de fundação de um Estado republicano requer um povo que não esteja corrompido de modo irremediável. Se assim for, esse povo não saberá discernir o interesse particular do público, ou as armadilhas daqueles que se dispõe a liderá-lo. Por isso que discernir as boas ações do Legislador dos interesses privados do tirano não é tarefa simples. Portanto, essa é uma das principais razões para Rousseau defender enfaticamente a participação popular nas decisões acerca dos rumos do Estado republicano.

O povo até que pode escolher - ou aceitar- ao invés de um Legislador, um tirano para conduzi-los nessa via para a instituição de um corpo político regido por um sistema de leis advindas da vontade popular. Apesar desse risco real, o que sabemos é que se for um tirano a soberania será usurpada; mas aí, uma vez que o povo preservará para si o poder soberano, tal inconveniente poderá ser contornado e conduzido ao caminho que se esperava originalmente. Nesse sentido, "a obra da legislação torna-se difícil menos pelo que é preciso estabelecer do que pelo que é preciso destruir, e o sucesso mostra-se tão raro dada a impossibilidade de encontrar a simplicidade da natureza associada às necessidades da sociedade" ${ }^{\prime 10}$. Enfim, apesar de parecer outra idealização do Genebrino, temos que ter claro que a maior responsabilidade para contornar tal inconveniente permanecerá nas mãos do povo. Por isso, a tirania deve ser uma preocupação e responsabilidade da totalidade do corpo político. Ao povo compete à vigilância constante, ao Legislador instituir os canais legais para que essa ameaça seja minimizada. O povo pode errar na escolha, mas teria meios institucionais para sair dele. Logo, tal risco não poderá ser totalmente eliminado, mesmo que o instituidor de leis seja um Legislador sábio e prudente, isto é, não há nenhuma garantia absoluta de que, até mesmo, essa

\footnotetext{
${ }^{9}$ ROUSSEAU. Du Contrat Social. In: Oeuvres Complètes-Gallimard, vol. 3, p. 390-1.

${ }^{10}$ Ibid., p. 39-40.
} 
figura excepcional transforme-se num agente de coação e usurpação do corpo político. Aí o alerta que nos faz Spitz:

aqueles que são colocados pelo pacto social sob a dependência de outrem não têm nenhum benefício real, pois a vida que se deixa a mercê daqueles cuja assistência lhes é necessária para sobreviver, irão forçá-los a servi-los em troca do sustento que lhe darão. ${ }^{11}$

Por outro lado, essa noção de povo ideal implica a ideia de uma legislação ideal, na qual identificamos uma problemática: como lidar com as mudanças internas e o desenvolvimento social? Na prática, as sociedades e as suas respectivas legislações tendem a certas mudanças ao longo de sua história. Aliás, segundo Baczko, "a legislação ideal visa, portanto, a estabilidade e a coerência da sociedade, reduzindo ao mínimo seu desenvolvimento e sua dinâmica interna" ${ }^{\text {"12 }}$. Essa é uma dificuldade que pressupõe a ação do Legislador, no momento da fundação do Estado, com vistas a compreender que uma sociedade deverá manter determinada maleabilidade sem, contudo, abrir mão dos seus princípios fundamentais, tais como a liberdade civil e a vontade geral. Aliás, nesse aspecto constatamos que Rousseau mostra-se conservador, ou seja, refratário à introdução frequente de novidades no Estado ${ }^{13}$. Tanto que, basta recordar que, ao tratar da República de Genebra, o autor elogiou a tradição e longevidade das suas leis ${ }^{14}$. Contudo, isso não significa que o autor seja avesso às mudanças. Podemos afirmar que, mudanças fazem-se necessárias, mudanças em demasia, não. Posto que, mudanças frequentes indicam bases mal formuladas e que precisam ser regularmente alteradas.

Dado que o conjunto desses fatores entre o povo e a legislação ideal é raro, um Estado bem constituído também o é. O que reforça o argumento da raridade e excepcionalidade do Legislador como um agente capaz de fazer face à corrupção e a desigualdade entre os homens. E, distintamente do tirano, o Legislador deverá orientar-se por aquilo que afirmamos

\footnotetext{
${ }^{11}$ SPITZ. La liberté politique: essai de généalogie conceptuelle, p. 353. Tradução nossa.

${ }^{12}$ BACZKO. Rousseau. Solitude et communauté, p. 381. Tradução nossa.

${ }^{13}$ Cf. Rousseau. Projet de Constitution pour la Corse. In: Oeuvres Complètes-Gallimard, vol. 3, p. 940-50.

14 "Je n'aurais point voulu habiter une République de nouvelle institution, quelques bonnes lois qu'elle pût avoir; de peur que le gouvernement autrement constitué peut-être qu'il ne faudrait pour le moment, ne convenant pas aux nouveaux citoyens, ou les citoyens au nouveau gouvernement, l'Etat ne fût sujet à être ébranlé et détruit presque dès sa naissance. (...) J'aurais donc cherché pour ma patrie une heureuse et tranquille république dont l'ancienneté se perdît en quelque sorte dans la nuit des temps; qui n'eût éprouvé que des atteintes propres à manifester et affermir dans ses habitants le courage et l'amour de la patrie, et où les citoyens, accoutumés de longue main à une sage indépendance, fussent, non seulement libres, mais dignes de l'être". ROUSSEAU. Discours sur l'origine et les fondements de l'inégalité parmi les hommes. In: Oeuvres Complètes-Gallimard, vol. 3, p. 112-3.
} 
acima: a "simplicidade da natureza associada às necessidades da sociedade"15. Somente assim é possível distingui-lo do tirano. Haja vista que o tirano tende para as riquezas, a servidão, às conquistas bélicas, a vontade particular ${ }^{16}$; por seu turno, o instituidor sábio privilegiaria a liberdade, a vontade geral, a população e a pa $^{17}$. Sabemos que, entre a virtude e o vício estará o destino da sociedade, cuja expressão máxima é a dinâmica inextinguível do homem e da sociedade. Vimos, portanto, como os homens e a sociedade foram aperfeiçoando seus potenciais e tornando a vida, ao invés de simples, em desigual e corrupta.

Diante dessa constatação podemos extrair algumas conclusões. Considerando a dinâmica interna da sociedade será inevitável que apareça alguma ameaça às instituições político-sociais e à soberania. $\mathrm{O}$ que naturalmente criaria um ambiente propício para que o tirano se fizesse notar como um agente excepcional capaz de fazer frente a essa necessidade da sociedade. Esclarecemos que esse "fazer frente" não passa de um recurso demagógico do referido tirano, para que o mesmo alcance o poder. Como consequência, o interesse particular se sobreporia ao geral. Contudo, se se tratar de um Estado republicano, o interesse geral deverá prevalecer e o tirano será tratado como uma ameaça e não como solução.

Entretanto, há outro inconveniente que poderá facilitar o aparecimento do tirano. Pressupondo que o Estado de leis não é um Estado distribuidor de bem aventurança ${ }^{18}$, temos que o mesmo não poderá fazer tudo por todos, algo há de ficar sem ser atendido. Se assim fosse, o Estado de leis seria fundado numa modalidade de soberania que obedeceria a seguinte equação: vontade geral = somatório de todas as vontades particulares. A vontade geral não é tal somatório, ela fundamenta-se nos aspectos gerais e comuns das vontades particulares ${ }^{19}$. Tal situação poderá, dada à dinâmica da sociedade, tornar-se um problema social. Tal problema social poderá evoluir e gerar uma convulsão interna no corpo político. E, Rousseau acredita que, diante de uma situação conflituosa há de prevalecer o tirano e os impulsos antissociais dos indivíduos. É nesse sentido que o autor afirma que, “o Estado não cessará de agitar-se até ser destruído ou modificado, e a natureza invencível retornar seu império"20. Aqui, diferentemente de Aristóteles ${ }^{21}$ e dos Enciclopedistas, o Genebrino não acredita que

\footnotetext{
${ }^{15}$ ROUSSEAU. Du Contrat Social. In: Oeuvres Complètes-Gallimard, vol. 3, p. 40.

${ }^{16}$ Cf. Masters. The Political Philosophy of Rousseau, p. 371.

${ }^{17}$ Cf. Rousseau. Du Contrat Social. In: Oeuvres Complètes-Gallimard, vol. 3, p. 393.

${ }^{18}$ Cf. Cassirer. A questão Jean-Jacques Rousseau, p. 60.

19 Cf. Rousseau. Du Contrat Social. In: Oeuvres Complètes-Gallimard, vol. 3, p. 368. Ver Machado apud ROUSSEAU. Textos Escolhidos/Rousseau. vol. I, p. 85.

${ }^{20}$ ROUSSEAU. Du Contrat Social. In: Oeuvres Complètes-Gallimard, vol. 3, p. 393.

${ }^{21}$ Cf. Aristóteles. Política, p. 15.
} 
predominem os impulsos racionais e sociabilizadores pressupostos como existindo na natureza humana. Nem a razão nem a sociabilidade impor-se-iam ao gênero humano.

Há aqui uma clara oposição entre o que podemos designar por "ordem natural" e "ordem social" 22 , isto é, entre o natural e o civilizado. E que reflete, em última instância, a prevalência dos instintos naturais sobre as necessidades coletivas. Isto, por sua vez, deixa explícito que nenhuma construção humana, por melhor que seja, pode resistir à inexorável dinâmica social. Assim, até mesmo um Estado renaturado ${ }^{23}$, orientado nas suas origens por um Legislador sábio e fundado em um sistema de leis soberanas, poderá ser mantido neste status quo indefinidamente. Essa é a própria "natureza invencível”, a qual poderá ser guiada, orientada, renaturada, corrompida, desnaturada, mas nunca suprimida.

Todo esse cenário, enfim, expõe outro fator essencial da antropologia e da política rousseauniana e que Goyard-Fabre expressa nos seguintes termos: "a mutação antropológica que, através do contrato, fez de um animal estúpido e limitado, um cidadão e um homem, caminha junto com uma metamorfose qualitativa e normativa, pela qual a justiça substitui o instinto" ${ }^{24}$. Essa é uma afirmação que reforça a noção da perfectibilidade ${ }^{25}$ humana e sua capacidade de transformar os homens e o seu entorno. Considerando a afirmação acima, acrescente-se que esse processo não se arremata nessa mutação que transformou o instinto do homem natural num conjunto de leis na sociedade civil. Há que se ter claro que nos encontramos diante de uma dinâmica inextinguível ou de uma "natureza invencível”. Até mesmo a mais bem constituída sociedade há de corromper-se e perecer.-Aliás, Salinas Fortes sustenta que

não se trata, para o Legislador, de 'desenhar um quadro de uma moral tão pura quanto as Leis de Platão', coisa que qualquer escolar poderia fazer, mas de organizar o poder e a vida coletiva numa sociedade dada, levando em conta as exigências do real empírico. ${ }^{26}$

Por isso, as ações dos cidadãos e do Legislador podem dar vida longa ao corpo político, desde que ambos não descuidem da sua finalidade maior: a conservação do interesse comum por

\footnotetext{
${ }^{22}$ Cf. Machado apud ROUSSEAU. Textos Escolhidos/Rousseau. vol. I, p. 129.

${ }^{23}$ Isto é, que saiu do estado de corrupção para o das virtudes republicanas (justiça, liberdade, igualdade, etc).

${ }^{24}$ GOYARD-FABRE. Politique et philosophie dans l'œuvre de Jean-Jacques Rousseau, p. 55. Tradução nossa.

${ }^{25}$ A perfectibilidade é uma inovação conceitual de Rousseau. Ela refere-se aos potenciais intrínsecos à natureza humana. Tais potenciais, ao longo do tempo, se atualizaram. A atualização pode se dar em qualquer sentido: indo dos piores vícios às mais altas virtudes.

${ }^{26}$ FORTES. Rousseau: da teoria à prática, p. 75. Grifos do autor.
} 
meio da vontade geral ${ }^{27}$. Caso contrário, o governo de um tirano e a corrupção do corpo político está à espreita de um povo que se perdeu em sua busca por uma sociedade bem ordenada, fruto da ação prudente do Legislador.

\section{Referências}

ARISTÓTELES. Política. Brasília: Editora UnB, 1988.

BACZKO, Bronislaw. Rousseau. Solitude et communauté. Traduzido do polonês por Claire Brendhel-Lamhout. Paris-La Haye: Mouton, 1974.

BIGNOTTO, Newton. As aventuras da virtude: as idéias republicanas na França do século XVIII. São Paulo: Companhia das Letras, 2010.

BURGELIN, Pierre. La Philosophie de l'Existence de Jean-Jacques Rousseau. Paris: PUF, 1952.

CASSIRER, Ernst. A questão Jean-Jacques Rousseau. São Paulo: Editora Unesp, 1999.

FORTES, Luiz Roberto Salinas. Rousseau: da Teoria à Prática. São Paulo: Ática, 1976.

GOYARD-FABRE, Simone. Politique et philosophie dans l'œuvre de Jean-Jacques Rousseau. Paris: PUF, 2001.

MASTERS, Roger D. The Political Philosophy of Rousseau. Princeton: Princeton University Press, 1968.

ROUSSEAU, Jean-Jacques. Textos Escolhidos/Rousseau. Tradução de Lourdes Santos Machado. São Paulo: Nova Cultural, 2 vol., 2000.

ROUSSEAU, Jean-Jacques. Du contrat social. Edição comentada por Maurice Halbwachs. Paris: Aubier-Montaigne, 1943.

ROUSSEAU, Jean-Jacques. Obras de Jean-Jacques Rousseau. Obras Políticas I. Rio de Janeiro, Porto Alegre e São Paulo: Editora Globo, 1958.

ROUSSEAU, Jean-Jacques. Oeuvres Complètes. Bernard Gagnebin e Marcel Raymond (orgs). Paris: Pléiade-Gallimard, 5 vol., 1959-1995.

ROUSSEAU, Jean-Jacques. Oeuvres Complètes. Jean Fabre e Michel Launay (orgs). Paris: L’Intégrale-Du Seuil, 3 vol.,1971.

SPITZ, Jean-Fabien. La liberté politique. Essai de généalogie conceptuelle. Paris: Presses Universitaires de France, 1995.

\footnotetext{
27 "o interesse comum é o único verdadeiramente visado pela vontade geral". BIGNOTTO. As aventuras da virtude: as idéias republicanas na França do século XVIII, p. 170.
} 